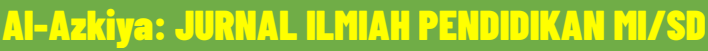 \\ ISSII: Print (2145-1653) Online (2521-8110) \\ Vol. 6 Ho.12021 \\ DOI 10.32505/al-arkiva.vil.2604
}

\section{Kesesuaian Muatan Pelajaran Bahasa Indonesia Kelas IV Tema Indahnya Kebersamaan SD/MI}

\author{
Aisyah Putri Deapalupi ${ }^{1}$, Eri Susanto ${ }^{2}$ \\ Universitas Islam Negeri Sunan Kalijaga Yogyakarta ${ }^{1,2}$ \\ ichadheaaisyah@gmail.com¹
}

\begin{abstract}
This study aims to analyze the content of Indonesian in terms of the use of sound and correct language and the suitability of image illustrations with the material in Theme 1 Beautiful Togetherness. This research uses a descriptive qualitative approach. The type of study chosen is in library research, which means that the researcher analyzes the teacher's book and student's book Theme 1, The Beauty of Togetherness. The method of quoting the data used is Forum Group Discussion (FGD). The result is Indonesian language learning material in Theme 1, The Beauty of Togetherness. It follows the EYD, and the illustrations used are apparent; however, some need correction not to misinterpret when the learning takes place.
\end{abstract}

Keywords: Content, Indonesian Language, Learning, Theme.

\begin{abstract}
Abstrak
Penelitian ini bertujuan menganalisis muatan Bahasa Indonesia dari sisi penggunaaan bahasa yang baik dan benar serta kesesuaian ilustrasi gambar dengan materi di Tema 1 Indahnya Kebersamaan. Penelitan ini menggunakan ancangan kualitatif deskriptif. Jenis peneliatan yang dipilih berupa studi pustaka (library research yang artinya peneliti menganalisis buku guru dan buku siswa Tema 1 Indahnya Kebersamaan. Cara pengutipan data yang dipakai adalah Forum Group Discussion (FGD). Hasilnya adalah materi pembelajaran Bahasa Indonesia yang ada di Tema 1 Indahnya Kebersamaan sudah sesuai dengan EYD dan ilustrasi yang digunakan sudah sangat jelas. Akan tetapi masih ada beberapa yang butuh koreksi agar tidak salah artikan oleh peserta didik saat pembelajaran berlangsung.
\end{abstract}

Kata kunci: Bahasa Indonesia, Konten, Pembelajaran, Tematik.

\section{PENDAHULUAN}

Sebahagian besar guru menggunakan buku ajar sebagai pegangan ketika melaksanakan pembelajaran di kelas (Estiningtyas, 2015). Buku adalah bahan tertulis yang mempersembahkan ilmu pengetahuan hasil buah pikir dari penulis. Oleh penulis isi buku diperoleh dari beraneka ragam cara, contohnya:

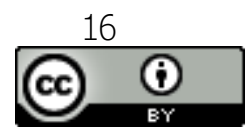

This work is licensed under a Creative Commons Attribution 4.0 International License 


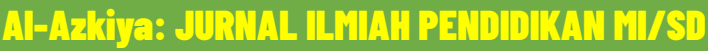 \\ ISSH: Print (2145-1656) Online (2527-8110) \\ Vol. 6 Ho.12021 \\ DOI $10.32505 / a 1-a k$ iva.10il.2904}

hasil pengkajian, hasil observasi, hasil realitas pengetahuan, atau hasil fantasi penulis yang dinamakan fiksi (Prastowo, 2014). Menurut BSNP, buku ajar yang bermutu wajib melengkapi empat kategori kepatutan, yaitu kepatutan isi, kepatutan penyajian, kepatutan kebahasaan, dan kepatutan kegrafikaan. Salah satu unsur yang harus diperhatikan, yaitu kelayakan isi (Wulandayani, 2015).

Buku ajar ini merupakan salah satu faktor tercapainya pelaksanaan Kurikulum 2013. Terutama berupa buku pembelajaran tematik. Buku tematik merupakan salah satu pedoman yang dipakai sebagai sumber belajar untuk memperoleh materi (Jantung, Delora, Saputra, \& Setiya, 2017). Menurut Permendiknas Nomor 11 Tahun 2005, buku teks pelajaran digunakan sebagai rujukan wajib yang berisi muatan pembelajaran menjadi bagian dari penambahan IMTAQ, moral dan karakter, kecakapan dalam IPTEK, sensibilitas dan kemampuan artistik, kemampuan diri dan kesehatan yang disusun berlandaskan standar nasional pendidikan (Mulyahati, 2014). Buku teks Kurikulum 2013 dibagi menjadi dua yaitu buku pegangan guru dan buku pegangan siswa.

Buku teks kurikulum 2013 diberikan kepada guru dan peserta didik sebagai panduan wajib dalam pembelajaran di kelas. Hingga saat ini buku teks masih diakui sebagai bahan mengajar utama dalam kegiatan pembelajaran. Buku teks dianggap penting karena dua hal yaitu berisi materi sesuai dengan kepentingan peserta didik dan bersifat praktis (Jantung, Delora, Saputra, \& Setiya, 2017). Buku siswa merupakan buku yang diterbitkan oleh Kemendikbud dibagikan ke seluruh pihak sekolah secara gratis. Buku ini disusun berdasarkan Kompetensi Inti dan Kompetensi Dasar yang ada di Kurikulum 2013, serta memperhatikan prinsip pendekatan scientific. Jenjang sekolah dasar materi dikembangkan dengan basic tematik-terpadu (Ruminiati \& Andjani, 2016).

Faktor lain yang mendukung tercapainya Kurikulum 2013 adalah proses pembelajaran di sekolah. Proses pembelajaran ini membutuhkan bahasa yang mengharuskan peserta didik saling berinteraksi, saling berbagi pengalaman dan

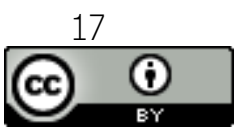

This work is licensed under a Creative Commons Attribution 4.0 International License 
menambah khasanah keilmuan diri. Hal tersebut sejalan dengan tujuan pembelajaran Bahasa Indonesia. Pembelajaran Bahasa Indonesia memiliki empat aspek kompetensi berbahasa yaitu mendengar, berbicara, membaca, dan menulis. Pembelajaran Bahasa Indonesia juga salah satu pembelajaran wajib dan pembelajaran penghela di sekolah dasar (Anzar, 2017).

Permasalahan yang muncul dari buku tematik guru dan peserta didik masih adanya materi pembelajaran Bahasa Indonesia yang tidak sinkron dan cenderung terdapat kesalahan walaupun direvisi setiap tahun. Kesalahan tersebut dari penggunaan Bahasa Indonesia yang baik dan benar berdasar EYD dan ilustrasi gambar yang tidak sesuai. Diharapkan dengan penelitian ini dapat membantu melacak kesalahan buku tematikAdapun tujuan penelitian ini adalah untuk menganalisis muatan Bahasa Indonesia dari sisi pemakaian bahasa yang baik dan benar serta kesesuaian ilustrasi gambar dengan materi di Tema 1 Indahnya Kebersamaan.

\section{METODE PENELITIAN}

Rancangan penelitian ini menggunakan pendekatan kualitatif yang berarti memfokuskan memahami subjek secara holistik. Metode yang dipakai merupakan metode deskripsi (Saidah \& Damariswara, 2017). Jenis penelitian yang dipakai adalah studi pustaka dengan cara menganalisis muatan Bahasa Indonesia di Tema 1 Indahnya kebersamaan. Objek penelitian merupakan buku guru dan buku siswa Tema 1 Indahnya Kebersamaan Kelas IV. Subjek penelitian merupakan kesesuaian muatan pembelajaran Bahasa Indonesia (Adi, 2017). Teknik pengumpulan data yang digunakan adalah analisis dokumen dan Forum Group Discussion (FGD). Teknik analisis dokumen dilakukan melalui observasi dan pencatatan yang teliti terhadap buku tema 1. Teknik FGD dilakukan dengan mencatat semua masukkan dan saran yang diberikan oleh peserta forum.

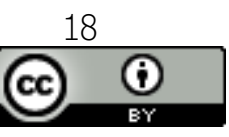

This work is licensed under a Creative Commons Attribution 4.0 International License 


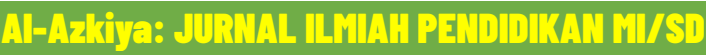 \\ ISSH: Print (2145-1656) Online (2527-8110) \\ Vol. 6 Ho.12021 \\ DOI 10.32505/al-arkiva.vil.2604}

\section{HASIL DAN PEMBAHASAN}

Hasil analisis mengenai pembelajaran Bahasa Indonesia di buku tematik menerangkan bahwa pembelajaran Bahasa Indonesia ada di setiap pembelajaran. Pembelajaran Bahasa Indonesia yang ada dibuku kelas IV semester I secara keseluruhan digabung dengan pembelajaran lain dengan Kompetensi Dasar yang sama. Penggabungan KD tersebut terdapat dalam Tema 1 Indahnya Kebersamaan, Tema 2 Selalu Berhemat Energi, Tema 3 Peduli Terhadap Makhluk Hidup, Tema 4 Berbagai Pekerjaan dan Tema 5 Pahlawanku. Pembelajaran Bahasa Indonesia terdapat di setiap subtema pembelajaran 1, 3, 4 , dan 6.

Berdasarkan analisis peneliti, Bahasa Indonesia merupakan bahasa penghela di antara semua pembelajaran. Sehingga seluruh pembelajaran dihubungkan dengan pembelajaran Bahasa Indonesia. Hasil pemetaan muatan Bahasa Indonesia Tema 1 Indahnya Kebersamaan dapat dilihat pada flowchart di bawah ini:

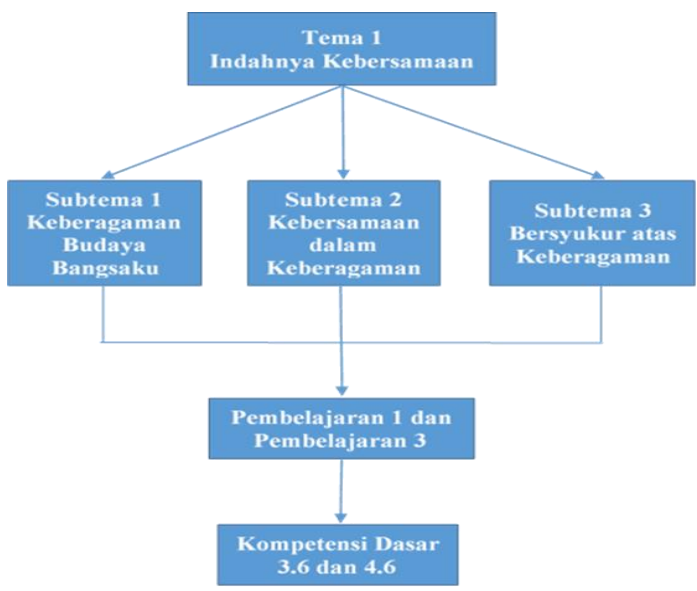

Gambar 1. Pemetaan Tema 1 Pembelajaran Bahasa Indonesia

Hal pertama yang dianalisis adalah pemakaian Bahasa Indonesia yang baik dan benar di buku siswa. Pembelajaran 1, 3, 4, dan 6 subtema 1 telah sesuai dengan Ejaan Yang Disempurnakan. Contohnya setiap kalimat perintah mudah dipahami oleh peserta didik, sehingga peserta didik mudah menjawab

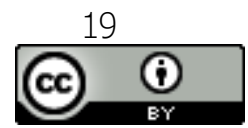

This work is licensed under a Creative Commons Attribution 4.0 International License 


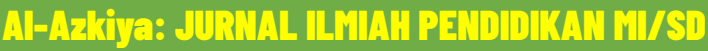 \\ ISSH: Print (2145-1656) Online (2521-8110) \\ Vol. 6 Ho.12021 \\ DOI 10.32505/al-arkiva.vil.2604}

pertanyaan. Hal kedua yang dianalisis adalah relevansi materi dengan ilustrasi gambar. Menurut peneliti, kalimat petunjuk di pembelajaran 1, 3, 4, dan 6 sudah relevan. Peserta didik diharapkan dapat belajar secara kontekstual dan mampu mengerjakan materi dengan mudah. Hal ini dibuktikan melalui gambar Tari Kipas Pakarena berasal dari Gowa Sulawesi Selatan di halaman 51 buku siswa. Peserta didik dapat membayangkan sususan tempat dalam tarian sehingga tidak membingungkan.

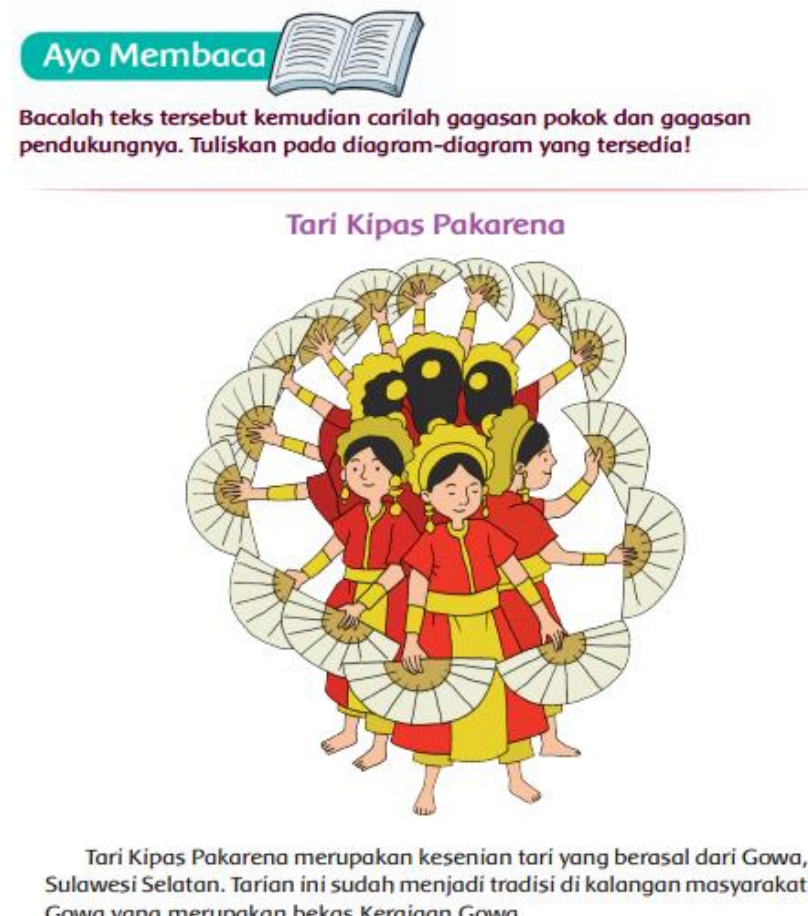

Gowa yang merupakan bekas Kerajaan Gowa.

Gambar 2. Tari Kipas Pakarena

Subtema 2 pembelajaran 1, 3, 4, dan 6 penggunaan Bahasa Indonesia sudah sesuai dengan EYD. Sehingga kalimat tanya dan kalimat perintah dalam paragraf menggunakan bahasa mudah dipahami peserta didik. Contohnya kalimat perintah "Ayo Membaca" di halaman 86 pembelajaran 2. Relevansi materi dengan ilustrasi gamabr di subtema 2 secara keseluruhan sudah relevan. Contohnya ada di halaman 87 pembelajaran 2 teks bacaan "Tong Sampah Gotong Royong". Gambar tong sampah dan barang bekas sudah dikumpulkan

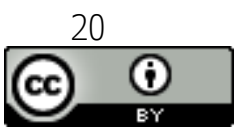

This work is licensed under a Creative Commons Attribution 4.0 International License 


\section{Al-Azkiya: JURHAL ILFHAH PEWDIDLAK HI/SD \\ 1SSIl: Print (2145-1653) Online (2527-8110) \\ Vol. 6 Ho.12021 \\ DOI 10.32505/al-arkiva.v6il.2904}

tetapi belum dibersihkan dan dicat. Gambar selanjutnya terdapat tong sampah dan barang bekas yang sudah dicat dan dibersihkan menjadi barang yang menarik. Teks dan gambar tersebut, peserta didik diharapkan dapat melihat bagaimana cara pemanfaatan barang bekas menjadi barang menarik.

Penggunaan Bahasa Indonesia yang baik dan benar di subtema 3 pembelajaran 1, 3, 4, dan 6 telah sesuai dengan Ejaan Yang Disempurnakan. Contohnya dihalaman 135 buku siswa "Percobaan Pemantulan dan Penyerapan Bunyi". Kalimat pecobaan dan kalimat perintah percobaan tersebut mudah dipahami peserta didik. Contoh lain dihalaman 138 "Ayo Renungkan" kalimat tanya jelas menanyakan tentang apa yang telah dipelajari dari kegiatan hari ini dan kendalanya apa saja.

Apa yang kamu pelajari dari kegiatan hari ini?

\section{Ayo Renungkan}

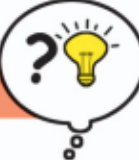

- Kesulitan apa yang kamu hadapi pada pembelajaran hari ini?

Gambar 3 Ayo Renungkan

Relevansi materi dengan ilustrasi gambar di subtema 3 telah relevan, tetapi perbedaan terlihat pada pembelajaran 3 halaman 145 buku siswa "Ayo Mencoba". Halaman tersebut tidak memuat ilustrasi gambar peserta didik bermain engklek dilapangan. Peserta didik tidak dapat mengaitkan cara bermain engklek sehingga secara tidak langsung harus membayangkan sendiri bagaimana bermain engklek. Pembelajaran 6 halaman 172, justru ada ilustrasi gambar petak engklek yang menggambarkan bangun datar di pembelajaran Matematika. Gambar pola petak engklek terdiri dari pola pesawat, pola gunung, dan pola bolang-baling.

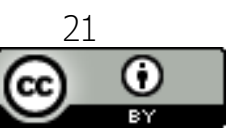

This work is licensed under a Creative Commons Attribution 4.0 International License 
Sebelumnya, perhatikan pola petak Engklek berikut.

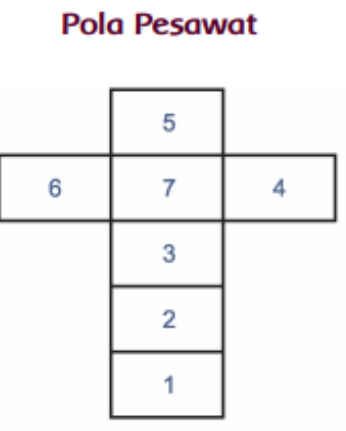

Pola Gunung

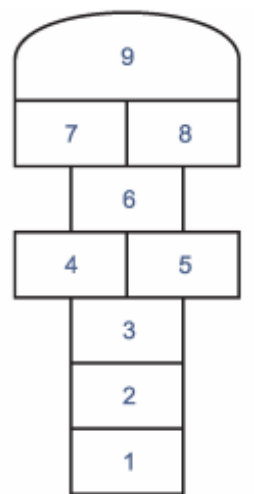

Pola Baling-baling

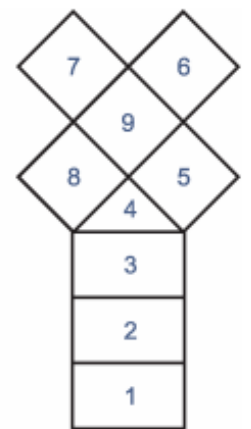

Gambar 4. Pola Petak Engklek

Menurut Rima Trianingsih dalam jurnal Ar-Risalah ditemukan bahwa pemakaian Bahasa Indonesia yang baik dan benar subtema 1 masih ada ketidaksesuaian bahasa dengan EYD. Salah satu ketidaksesuaian tersebut adalah pemakaian kata tidak baku kalimat dan ejaan bacaan yang salah. Selanjutnya, relevansi materi dengan ilustrasi gambar sudah bagus tetapi ilustrasi gambar yang digunakan belum jelas sehingga peserta didik kurang memahami ilustrasi gambar dengan materi (Trianingsih, 2016).

Sedangkan hasil analisis peneliti, pemakaian Bahasa Indonesia yang baik dan benar sudah sesuai antara ilustrasi gambar dengan relevansi materi. Hal ini dikarenakan buku yang dianalisis oleh peneliti dengan buku yang dianalisis Rima berbeda tahun revisinya. Peneliti menggunakan buku tematik revisi 2017, sedangkan Rima menggunakan revisi tahun 2016. Adapun hasil analisis peneliti hanya seputar EYD dan relevansi materi dengan ilustrasi gambar. Hasil analisis tersebut diharapkan dapat dijadikan bahan pertimbangan revisi buku ditahun mendatang.

Hasil analisis dari Arif dan Ali dalam jurnal Profesi Pendidikan Dasar ditemukan bahwa buku teks Non-Kemendikbud 1 dan 2 masuk dalam kategori baik dengan rentang persentase 77\%-83\%. Walaupun sudah termasuk kategori

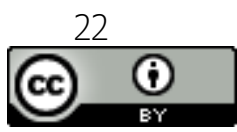

This work is licensed under a Creative Commons Attribution 4.0 International License 


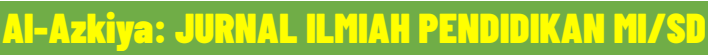 \\ ISSH: Print (2145-1656) Online (2527-8110) \\ Vol. 6 Ho.12021 \\ DOI $10.32505 / a 1-a k$ iva.10il.2904}

baik masih terdapat kekurangan penggunaan EYD-nya. Buku teks NonPermendikbud 1 terdapat di penggunaan ilustrasi yang tidak selaras dan pemilihan kata yang kurang sesuai dengan tumbuh kembang peserta didik. Buku teks Non-Permendikbud 2 pemakaian tanda baca yang kurang tepat dengan tumbuh kembang peserta didik dan kurang selarasnya penggunaan ikon (Purnanto \& Mustadi, 2016).

\section{KESIMPULAN}

Secara umum pendidikan yang dilaksanakan ditingkat sekolah SD/MI sudah masuk dalam kategori baik dari sebelumnya sesuai dengan ketentuan yang berlaku seperti di permendikbud. Materi pembelajaran Bahasa Indonesia yang ada di Tema 1 Indahnya Kebersamaan sudah sesuai dengan EYD dan ilustrasi yang digunakan sudah sangat jelas. Akan tetapi masih ada beberapa yang butuh koreksi agar tidak salah artikan oleh peserta didik saat pembelajaran berlangsung. Saran untuk perbaikan kedepan alangkah lebih baiknya kompetensi dasar yang ada dibuku tematik berbeda disetiap temanya agar peserta didik bisa lebih banyak mendapatkan beragam materi tidak hanya fokus dimateri pada satu kompetensi dasar.

\section{DAFTAR PUSTAKA}

Adi, Y. K. (2017). Analisis Muatan Pendidikan Karakter Dalam Buku Teks Kurikulum 2013 Kelas III SD Semester 1. Jurnal Profesi Pendidikan Dasar, 4(1).

Anzar, S. F. (2017). Analisis Kesulitan Belajar Siswa Pada Pembelajaran Bahasa Indonesia Di Kelas V SD Negeri 20 Meulaboh Kabupaten Aceh Barat Tahun Ajaran 2015/2016. Jurnal Bina Gogik, 4(1), 53-64.

Estiningtyas, N. N. (2015). Analisis Kesesuaian Buku Ajar Tema Indahnya Kebersamaan Kelas IV SD Dengan Kurikulum 2013. Trihayu : Jurnal Pendidikan Ke-SD-an, 1(3), 185-190.

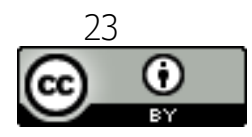

This work is licensed under a Creative Commons Attribution 4.0 International License 


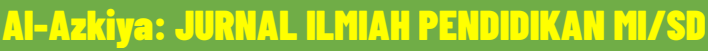 \\ ISSII: Print (2145-1653) Online (2521-8110) \\ Vol. 6 Ho.12021 \\ DOI 10.32505/al-arkiva.vil.2604}

Jantung, A., Delora, Saputra, Y., \& Setiya. (2017). Analisis Kelayakan Buku Siswa Kelas IV Tema Makhluk Hidup Kurikulum 2013. Pedagogia : Jurnal Pendidikan, 6(1), 99.

Mulyahati, B. (2014). Analisis buku tematik terpadu kurikulum 2013 Kelas IV Sekolah Dasar. Bogor: Universitas Pendidikan Indonesia.

Prastowo, A. (2014). Pengembangan Bahan Ajar Tematik. Jakarta: Renada Media Group.

Purnanto, A. W., \& Mustadi, A. (2016). Analisis Kelayakan Bahasa Dalam Buku Tema 1 Kelas 1 Sekolah Dasar Kurikulum 2013. Jurnal Profesi Pendidikan Dasar, 3(2), 102-111.

Ruminiati, \& Andjani, K. (2016). Analisis Kesesuaian Isi Buku Tematik Kelas IV Sekolah Dasar Dengan Pendidikan Karakter, dan Pendekatan Scientific. Jurnal Sekolah Dasar, 25(1).

Saidah, K., \& Damariswara, R. (2017). Analisis Bentuk Bentuk Penilaian Sikap Siswa Sekolah Dasar Di Kota Kediri. Jurnal Profesi Pendidikan Dasar, 4(1).

Trianingsih, R. (2016). Analisis Buku Kelas V SD/MI Kurikulum 2013 Pada Tema Kerukunan Dalam Bermasyarakat. Jurnal Ar-Risalah, 17(1).

Wulandayani, d. (2015). Analisis Isi Buku Ajar Bahasa Indonesia Wahana Pengetahuan Untuk SMP/MTs Kelas VIII", Jurnal Penelitian Bahasa dan Sastra Indonesia dan Pengajarannya. 3(2), 3.

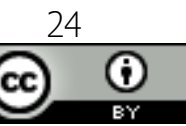

This work is licensed under a Creative Commons Attribution 4.0 International License 